\title{
What is the role of self-compassion on subjective happiness and life satisfaction?
}

\author{
Öznur Çağlayan Mülazım ${ }^{1}$ \\ Jale Eldeleklioğlu
}

\begin{abstract}
The aim of this study was to investigate the relationship between self-compassion and subjective happiness and the relationship between self-compassion and life satisfaction. Participants were composed of 252 undergraduate students in Bursa, Turkey. Self-compassion Scale, Subjective Happiness Scale, and Satisfaction with Life Scale were used as data collection instruments. Correlation analysis was used to examine the relationship between self-compassion, subjective happiness and life satisfaction. The hypothesis model was tested through structural equation modeling. Results of correlation analysis showed that self-kindness, common humanity, and mindfulness were positively, self-judgment and isolation were negatively related to subjective happiness and life satisfaction. While over-identification was negatively associated with subjective happiness, there was no correlation between over-identification and life satisfaction. The model fitted well $\left(\chi^{2} / \mathrm{df}=1, \mathrm{GFI}=.99, \mathrm{CFI}=1, \mathrm{NFI}=.99, \mathrm{AGFI}=.98, \mathrm{SRMR}=.00, \mathrm{RMSEA}=.00\right)$. According to path analysis results, subjective happiness and life satisfaction were predicted positively by common humanity, and mindfulness. Moreover, subjective happiness and life satisfaction were predicted negatively by self-judgment, isolation, and over-identification.
\end{abstract}

Keywords: Self-compassion; Subjective happiness; Life satisfaction; Positive Psychology; Path analysis.

\section{Introduction}

In recent years, with the emergence of positive psychology approach, the focus of psychology has changed from healing only the negative aspects of individuals to building one's positive qualities (Seligman \& Csikszentmihalyi, 2000). Positive psychology movement underlines human strengths and potentials such as love, happiness, wisdom and growth rather than weaknesses and damage (Sheldon \& King, 2001). Self-compassion which dates back to Buddhist philosophy is one of the important concepts of positive psychology and it is defined as being gentle and understanding towards oneself when confronting difficulties, adopting noncritical attitude towards one's failures, and accepting life experiences as part of human lives (Neff, 2003a). It also involves being aware of one's own sufferings and inadequacies, and accept oneself as an imperfect human being (Neff, 2003b; Neff, Kirkpatrick, \& Rude, 2007).

Neff $(2003 a, b)$ stated that self-compassion contains three main components: self-kindness versus self-judgment, common humanity versus isolation, and mindfulness versus overidentification. Although those three components are conceptually different, they interact with each other in order to strengthen one another (Neff, 2004). Self-kindness refers to being caring and considerate with oneself rather than being harshly self-critical and judgmental (Neff, 2003a), and it requires being kind and gentle to oneself when s/he suffers due to uncontrollable life events or

\footnotetext{
${ }^{1}$ Ph.D. Student, Uludağ University, Faculty of Education, Guidance and Psychological Counseling; oznrca@gmail.com
}

2 Prof. Dr., Uludağ University, Faculty of Education, Guidance and Psychological Counseling; eldelek@uludag.edu.tr 
Çağlayan Mülazım, Ö., \& Eldeleklioğlu, J. (2016). What is the role of self-compassion on subjective happiness and life satisfaction? Journal of Human Sciences, 13(3), 3895-3904. doi:10.14687/jhs.v13i3.4001

personal weaknesses and failings (Neff \& Beretvas, 2012). Instead of attacking and criticizing oneself for personal flaws, the self is offered warmth and unconditioned acceptance (Albertson, Neff \& Dill-Shackleford, 2014). Common humanity, the second dimension of self-compassion, involves accepting that one's experiences are not separated and isolated from others', they are part of the larger human experiences (Neff, 2003a). With the sense of common humanity, selfcompassionate individual is aware that humans are fallible and that all people make mistakes and have important life challenges (Neff \& Germer, 2013). In addition to this, the awareness of common humanity highlights individual's connectedness to other people (Barnard \& Cury, 2011). Finally, mindfulness is described as balancing awareness of one's emotions rather than overidentifying with them (Neff, 2003a), which means being conscious of one's painful thoughts and feelings without avoiding and exaggerating them (Neff, Hsieh, \& Dejitterat, 2005). It is also essential to be open to one's own sufferings in order to be able to extend compassion towards oneself (Neff, 2009).

Although self-compassion is a relatively new topic, many studies have indicated that selfcompassion is strongly related to psychological well-being. Research has found that selfcompassion is positively associated with self-determination (Neff, 2003a), life satisfaction and connectedness (Neff, 2003b), psychological well-being (Neff, 2003a; Neff, Kirkpatrick \& Rude, 2007), happiness (Neff \& Germer, 2013), achievement goals (Neff, Hsieh, \& Dejitterat, 2005), better emotional coping skills (Neff, Hseih, \& Dejitthirat, 2005), optimism, wisdom, curiosity (Neff, Rude \& Kirkpatrick, 2007), positive romantic relationship behavior (Neff \& Beretvas, 2012), and subjective happiness (Akın \& Akın, 2014). On the other hand, self-compassion is negatively associated with depression, anxiety, rumination and neurotic perfectionism (Krieger, Altenstein, Baettig, Doerig, \& Holtforth, 2013; Neff, Pisitsungkagarn \& Hseih, 2008), self-criticism (Neff, Rude \& Kirkpatrick, 2007).

\section{Subjective happiness}

Happiness is one of the most noticeable and important dimensions of human experience (Lyubomirsky, 2001), and it is often called subjective well-being which means experiencing more positive, less negative feelings and having high life satisfaction (Myers \& Diener, 1995). While some people consider themselves happy despite difficulties and poor life conditions, there are also people who consider themselves unhappy even if they live in better conditions (Lyubomirsky \& Lepper, 1999). Being happy in stressful situations and being unhappy in good conditions can be explained with subjective processes in happiness (Myers \& Diener, 1995).

Specifically, subjective happiness is defined as individuals' subjective evaluations of their being happy or unhappy (Lyubomirsky \& Lepper, 1999). It has been clarified that rather than real life experiences, how individuals perceive, recall, and interpret those experiences affect their happiness, and happy people perceive and interpret life experiences and conditions more positively than unhappy people (Lyubomirsky \& Tucker, 1998). Studies have illustrated that subjective happiness is positively related to perceived health status and life satisfaction (Lin, Lin, \& Wu, 2010), social support (Le, Lai \& Wallen, 2009), positive feelings (Diener \& Seligman, 2002), mental health (Liem, Lustig \& Dillon, 2010), self-compassion (Akın \& Akın, 2014). On the other hand, there are negative correlations between subjective happiness and depressive symptoms (Chaplin, 2006), and stress (Schiffrin \& Nelson, 2010).

\section{Life satisfaction}

Subjective well-being, which is individual's cognitive and affective evaluations about one's own life, has three components: presence of positive affect, infrequency of negative affect, and life satisfaction (Myers \& Diener, 1995). While presence of positive affect and infrequency of negative affect constitute affective domain of subjective well-being, life satisfaction is cognitive part of it (Diener, 2000; Myers \& Diener, 1995). Life satisfaction is described as general cognitive judgment 
Çağlayan Mülazım, Ö., \& Eldeleklioğlu, J. (2016). What is the role of self-compassion on subjective happiness and life satisfaction? Journal of Human Sciences, 13(3), 3895-3904. doi:10.14687/jhs.v13i3.4001

of individual's life according to one's own criteria (Pavot \& Diener, 1993). The assessment of life satisfaction is based on an individual's own standards; an individual evaluates how satisfying his/her life is depending on his/her chosen criteria rather than externally imposed criteria (Diener, Emmons, Larsen, \& Griffin, 1985).

It has been shown that life satisfaction may have a role as a protective factor against the development of psychopathology (Suldo \& Huebner, 2004). People high in life satisfaction experience positive feelings more often and they have high subjective well-being as well (Deiner \& Lucas, 1999). Moreover, people more satisfied with their lives are inclined to experience better mental and physical health (Siahpush, Spittal, \& Singh, 2008). Studies have shown that life satisfaction is positively related to self-esteem (Shek, 2005), perceived social support (Edwards \& Lopez, 2006), self-compassion (Neff \& Germer, 2013; Smeets, Neff, Alberts, \& Peters, 2014), and subjective happiness (Uysal, Satıc1, Satıc1, \& Akın, 2014). On the other hand, other studies have demonstrated that life satisfaction is negatively associated with stress and loneliness (Goodwin, Cook, \& Yung, 2001), anxiety and depression (Serin, Serin, \& Özbaş, 2010), and risky behaviors (Savi-Çakar, Tagay, \& Karataş, 2015).

\section{The Present Study}

Self-compassion involves taking a kind and understanding attitude toward oneself rather than being harshly self-critical and judgmental (Neff, 2003a). Giving up harsh self-criticism and being understanding to oneself protect an individual against rumination, depression, and anxiety (Neff, Hsieh, \& Dejitterat, 2005; Neff, Kirkpatrick, \& Rude, 2007). Self-compassion fosters well-being by helping individuals feel cared for, connected, and emotionally calm (Gilbert, 2005). It is stated that individuals who have high self-compassion are psychologically healthier than those who have low self-compassion owing to the lack of harsh self-judgment, feelings of separation, and overidentification with negative thoughts and emotions (Neff, 2003b). Also, being aware of one's own failures and inadequacies and having caring and compassionate attitude toward oneself instead of being critical one enable an individual to improve positive feelings about oneself in stressful situations (Leary, Tate, Adams, Allen, \& Hancock, 2007; Neff and Beretvas, 2012). In addition to these, feeling of warmth, connection with others, and balanced awareness that self-compassion offers make people happier (Neff, 2003b). An individual who has high self-compassion tend to be in a more positive and less negative mood and becomes happier (Neff, Rude, \& Kirkpatrick, 2007).

People who experience positive emotions more than negative emotions have higher life satisfaction in addition to being happier (Deiner \& Lucas, 1999). When life conditions are stressful, a self-compassionate response requires taking a break first to soothe and comfort oneself instead of instantly trying to control or solve the problem (Smeets, Neff, Alberts, \& Peters, 2014). Individuals who are high in self-compassion perceive sufferings and negative experiences as a natural process of human life (Neff, 2003a), display higher levels of optimism, gratitude and positive affect and have greater life satisfaction (Breen, Kashdan, Lenser, \& Fincham, 2010). Self-compassion can also predict well-being and life satisfaction by protecting individuals against distressing emotional and cognitive reactions going with difficult life circumstances (Allen, 2011).

\section{The purpose of the study}

Based on the related literature on self-compassion, subjective happiness and life satisfaction, the purpose of this study was to investigate the relationships between self-compassion and subjective happiness and life satisfaction. Although the relationship between self-compassion and subjective happiness (Akın \& Akın, 2014 ) and life satisfaction (Uysal, 2014) has been examined separately, the relationship between those variables has not been investigated together. Drawing upon the purpose, it was hypothesized that subjective happiness and life satisfaction would be predicted positively by self-kindness, common humanity, and mindfulness, and negatively by self-judgment, isolation, and over-identification. 
Çağlayan Mülazım, Ö., \& Eldeleklioğlu, J. (2016). What is the role of self-compassion on subjective happiness and life satisfaction? Journal of Human Sciences, 13(3), 3895-3904. doi:10.14687/jhs.v13i3.4001

\section{Method}

\section{Participants}

The target population was all university students in Turkey. However, the accessible population was 252 university students enrolled in various undergraduate programs at Uluda $\breve{g}$ University Faculty of Education and Faculty of Arts and Science in Bursa, Turkey. These programs included social sciences education, mathematics education, science education, Turkish education, English Language education, German Language education and guidance and psychological counseling. In this study, convenience sampling was used as a non-random sampling method. Of the 252 participants, 174 were female $(69 \%)$ and 78 were male (31\%), and the mean age was $22.5 \pm 3.11$.

\section{Measures}

Self-Compassion scale (SCS). The scale was developed by Neff (2003b) and it is composed of 26 self-report items. The scale consists of six sub-scales (self-kindness, common humanity, mindfulness, self-judgment, isolation, and over-identification). Each item is rated on a 5-point Likert scale (from $1=$ strongly disagree to $5=$ strongly agree). Adaptation of the scale was carried out by Akın, Akın and Abac1 (2007). Confirmatory factor analysis results for the six factor model of the Turkish version SCS yielded following goodness of fit indices: $\left[\chi^{2}=779.01, \mathrm{p}=.00\right.$; GFI $=.91$, $\mathrm{CFI}=.97, \mathrm{RMSEA}=.06, \mathrm{SRMR}=.06]$. The internal consistency coefficients were $.77, .72, .72$, $.80, .74$, and .74 and the test-retest reliability coefficients were $.69, .59, .66, .60 .69$, and .56 , for six subscales, respectively. The internal consistency reliability obtained for the SCS in the current study was .92.

Subjective happiness scale (SHS). The scale was developed by Lyubomirsky and Lepper (1999). The SHS is a unidimensional measure of global happiness which consists of four items using a Likert scale from 1 (strongly disagree) to 7 (strongly agree). A sum of all scores yields a total score that ranges from 4 to 28 , with a higher score indicating a higher subjective happiness. The Turkish adaptation of this scale was performed by Akın and Satıc1 (2011). Results of confirmatory factor analysis indicated that the unidimensional model was well fit to Turkish population (x 2 $/ \mathrm{df}=0.71, \mathrm{p}=0.49193, \mathrm{RMSEA}=.000, \mathrm{NFI}=.99, \mathrm{CFI}=1.00, \mathrm{IFI}=1.00, \mathrm{RFI}=.98, \mathrm{GFI}=1.00$, AGFI=.99, and SRMR=.015). The internal consistency reliability coefficient of the scale was found to be .86 and the test-retest reliability coefficient was found to be .73 . The internal consistency reliability obtained for the SHS in the current study was .73.

The satisfaction with life scale (SWLS). The scale was developed by Diener, Emmons, Larse, and Griffin (1985). The SWLS is a unidimensional measure of life satisfaction which consists of five items using a Likert scale from 1 (strongly disagree) to 7 (strongly agree). A sum of all scores yields a total score that ranges from 5 to 35, with a higher score indicating a higher life satisfaction level. The Turkish adaptation of this scale was performed by Durak, Senol-Durak, and Gencoz (2010) and they found the internal consistency coefficient to be .81. The results of the confirmatory factor analysis indicated that the model was well fitted $(\mathrm{x} 2 / \mathrm{d}(\mathrm{f})=2.026$, IFI $=.994$, TLI $=.987, \mathrm{CFI}=.994, \mathrm{SRMR}=.020$, and RMSEA $=.043)$. The internal consistency reliability obtained for the SWLS in the current study was .86.

\section{Procedure and data analysis}

The study was conducted during a one-month period in the spring term of 2015. The questionnaires were distributed to the participants by the researcher. The students were informed about the aim and the measurement of the study in advance, and only volunteers were asked to participate. Completion of the questionnaires was anonymous and there was a guarantee of confidentiality. The participants answered the questionnaires in approximately 20 minutes. In this study, Pearson correlation coefficient was applied to assess statistical significance for the relations of self-compassion with subjective happiness and life satisfaction. To test the hypothesis model, 
Çağlayan Mülazım, Ö., \& Eldeleklioğlu, J. (2016). What is the role of self-compassion on subjective happiness and life satisfaction? Journal of Human Sciences, 13(3), 3895-3904. doi:10.14687/jhs.v13i3.4001

structural equation modeling (SEM) was used and analyses were carried out with AMOS 22.0 and IBM SPSS Statistics 15.

\section{Results}

\section{Descriptive data and inter-correlations}

Table 1 shows the means, standard deviations, and Pearson correlation coefficients for the variables.

Table 1

Descriptive statistics and inter-correlations of the variables

\begin{tabular}{|c|c|c|c|c|c|c|c|c|}
\hline Variables & 1 & 2 & 3 & 4 & 5 & 6 & 7 & 8 \\
\hline \multicolumn{9}{|l|}{ 1. Subjective happiness } \\
\hline \multicolumn{9}{|l|}{ 2. Life satisfaction } \\
\hline 3. Self-kindness & $.44^{* *}$ & $.33^{* *}$ & & & & & & \\
\hline 4. Self-judgment & $-.42^{* *}$ & $-.28 * *$ & $-.50^{* *}$ & & & & & \\
\hline 5. Common humanity & $.43^{* *}$ & $.34^{* *}$ & $.61^{* *}$ & $-.41^{* *}$ & & & & \\
\hline 6. Isolation & $-.39^{* *}$ & $-.26^{* *}$ & $-.40^{* *}$ & $.68^{* *}$ & $-.33^{* *}$ & & & \\
\hline 7. Mindfulness & $.47^{* *}$ & $.36^{* *}$ & $.73^{* *}$ & $-.47^{* *}$ & $.56^{* *}$ & $-.44^{* *}$ & & \\
\hline 8. Over-identification & $-.18^{* *}$ & $.02^{* *}$ & $-.32^{* *}$ & $.62^{* *}$ & $-.24^{* *}$ & $.60^{* *}$ & $-.32^{* *}$ & \\
\hline Mean & 4.66 & 4.35 & 3.19 & 2.45 & 3.11 & 2.67 & 3.29 & 3.31 \\
\hline Standard Deviation & 1.11 & 1.25 & .79 & .87 & .83 & .86 & .82 & .96 \\
\hline Skewness & -.67 & -.45 & -.21 & .72 & -.05 & .38 & -.26 & -.28 \\
\hline Kurtosis & .76 & .09 & -.15 & .24 & -.56 & -.33 & -.09 & -.64 \\
\hline Cronbach's $\alpha$ & .73 & .86 & .78 & .83 & .75 & .72 & .80 & .78 \\
\hline
\end{tabular}

Note: ${ }^{* *} p<.01$

When Table 1 is examined, it is seen that the correlational analysis revealed significant relationships between the research variables. Correlations between self-compassion and subjective happiness were statistically significant. According to the results of the Pearson product moments correlation coefficient analysis, self-kindness $(r=.44, p<0,05)$, common humanity $(r=.43, p<0,05)$ and mindfulness $(r=.47, p<0,05)$ related positively to subjective happiness. On the other hand, selfjudgment $(r=-.42, p<0,05)$, isolation $(r=-.39, p<0,05)$ and over-identification $(r=-18, p<0,05)$ were found negatively associated with subjective happiness.

As can be seen, correlations between self-compassion and life satisfaction were also statistically significant. Self-kindness $(r=.33, p<0,05)$, common humanity $(r=.34, p<0,05)$ and mindfulness $(r=.36, p<0,05)$ related positively to life satisfaction. On the other hand, self-judgment $(r=-.28$, $p<0,05)$, and isolation $(r=-.26, p<0,05)$ were found negatively associated with life satisfaction. However, there is no significant correlation between over-identification $(r=.02, p<0,05)$ and life satisfaction.

\section{Structural equation modeling}

The results of SEM analysis presented in Figure 1. The model demonstrated fit $(\chi 2 / \mathrm{df}=1$, $\mathrm{GFI}=.99, \mathrm{CFI}=1, \mathrm{NFI}=.99$, AGFI $=.98$, SRMR $=.00$, RMSEA $=.00$ ) and accounted for $33 \%$ of subjective happiness and $22 \%$ of life satisfaction variance. 
Çağlayan Mülazım, Ö., \& Eldeleklioğlu, J. (2016). What is the role of self-compassion on subjective happiness and life satisfaction? Journal of Human Sciences, 13(3), 3895-3904. doi:10.14687/ihs.v13i3.4001

The standardized coefficients in Figure 1 clearly showed that subjective happiness was predicted positively by common humanity $(\beta=.16)$ and mindfulness $(\beta=.19)$ and predicted negatively by selfjudgment $(\beta=-.20)$, isolation $(\beta=-.20)$ and over-identification $(\beta=-.20)$. It can also be seen from Figure 1 that life satisfaction was predicted positively by common humanity $(\beta=.15)$ and mindfulness $(\beta=.18)$ and predicted negatively by self-judgment $(\beta=-.19)$ isolation $(\beta=-.17)$ and over-identification $(\beta=-.31)$. However, the path from self-kindness to subjective happiness and the path from self-kindness to life satisfaction were not significant.

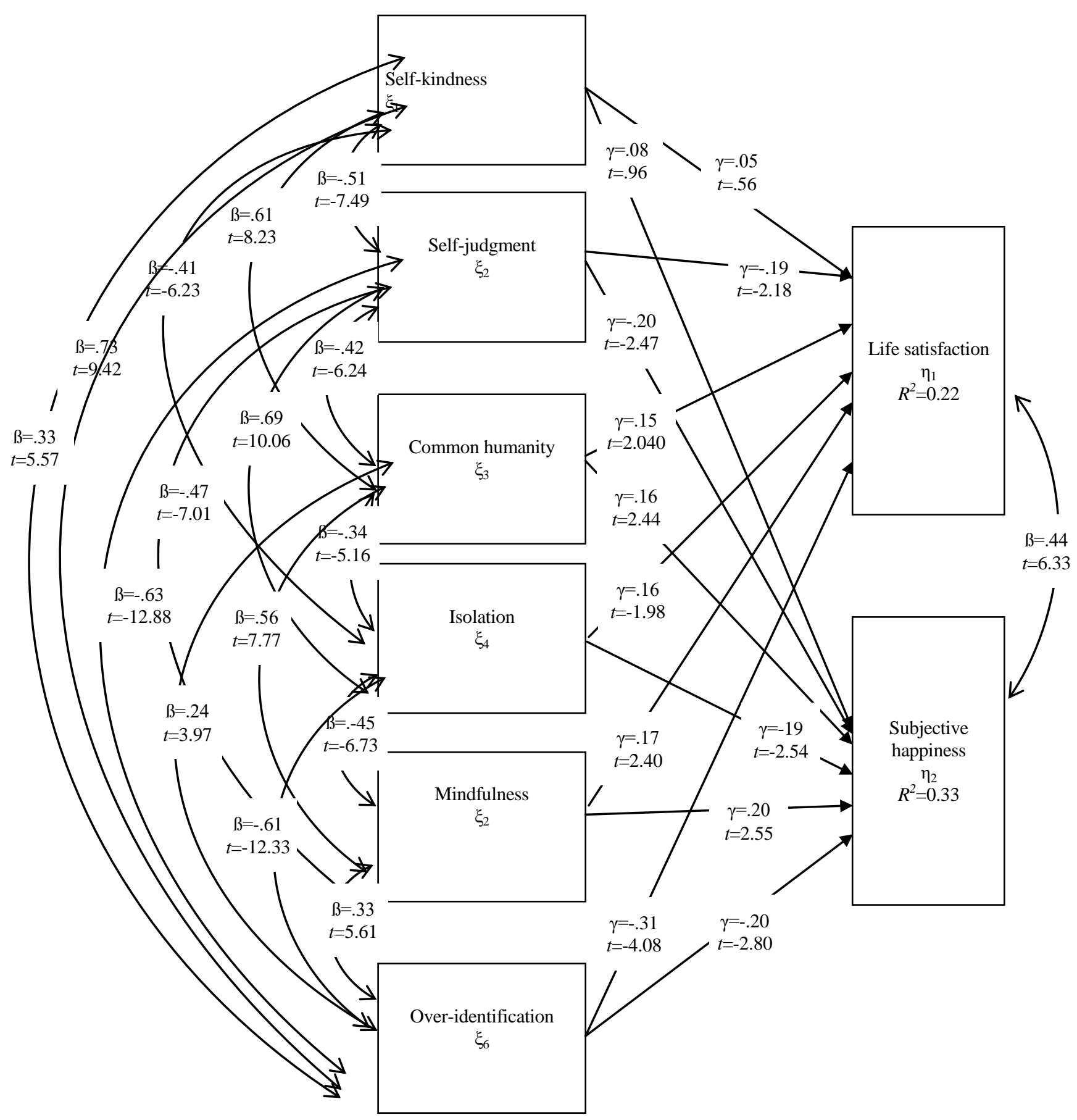

Figure 1. Path analysis between self-compassion and subjective happiness and life satisfaction 
Çağlayan Mülazım, Ö., \& Eldeleklioğlu, J. (2016). What is the role of self-compassion on subjective happiness and life satisfaction? Journal of Human Sciences, 13(3), 3895-3904. doi:10.14687/jhs.v13i3.4001

\section{Discussion}

The purpose of this research is to investigate the relationships between self-compassion and subjective happiness and life satisfaction. The findings of the present study have demonstrated that there are significant relationships between the dimensions of self-compassion and subjective happiness and life satisfaction. As expected, path analysis showed that subjective happiness and life satisfaction were predicted positively by common humanity and mindfulness and the findings are in line with reported previous studies. Common humanity and mindfulness are positive dimensions of self-compassion, and these dimensions involve accepting oneself as a part of the larger human experiences and having balanced awareness of one's emotions (Barnard \& Curry, 2011; Neff, 2003a). People with high self-compassion are aware of their sufferings and they behave warmly towards themselves, maintain their contact with others, and so they experience more positive and less negative feelings (Neff, 2003b). Thus, people experiencing more positive feelings tend to be happier than others (Myers \& Diener, 1995).

Akın and Akin (2014) investigated the relationship between the dimensions of self-compassion and subjective happiness and they found that self-kindness, common humanity and mindfulness are positively related to self-compassion, however, self-judgment, isolation and over-identification were negatively related to subjective happiness. Self-compassionate individuals accept negative life experiences as part of human life, and they get more life satisfaction with the feelings of optimism and gratitude (Neff, 2003a; Umphrey \& Sherblom, 2014). In parallel with the present study, Neff and Germer (2013) have clarified that after participating in a self-compassionate program, individuals' not only subjective happiness but also life satisfaction increased. Uysal (2014) has examined the relationship between the dimensions of self-compassion and life satisfaction, and the findings of the study illustrated that self-kindness, common humanity, and mindfulness were positively associated with life satisfaction.

The findings of this study also demonstrated that subjective happiness and life satisfaction were predicted negatively by self-judgment, isolation and over-identification which are negative dimensions of self-compassion. When individuals face failure and inadequacy, they focus on negative feelings, criticize and judge themselves, and feel isolated (Neff, 2003a; Neff \& McGehee, 2010). Previous studies have shown that self-judgment, isolation, and over-identification are positively related to anxiety, depression, rumination and neurotic perfectionism (Neff, 2003a, b; Neff, Rude \& Kirkpatrick, 2007), and negatively related to happiness (Akın \& Akın, 2014) and life satisfaction (Uysal, 2014). An individual evaluates one's life according to his or her own standards (Pavot \& Diener, 1993). When self-compassionate people do not meet their standards, they accept the present situation and have more satisfaction with life (Neff, 2003b). Smeets and et al., (2014) have indicated that there is a positive relation between self-compassion and life satisfaction, and when an individual's self-compassion increases, one's life satisfaction increases as well. Although subjective happiness and life satisfaction were negatively predicted by self-judgment, self-kindness was not associated with subjective happiness and life satisfaction in this study. Neff (2003b) has stated that an individual may not judge oneself, but it does not necessarily mean that $\mathrm{s} /$ he typically tends to be kind to oneself, either. Also, Neff, Pisitsungkagarn and Hsieh (2008) have clarified that culture may have an impact on the components of self-compassion differently, so the result can be explained by the structure of the participants' culture.

\section{Limitations of the Current Study}

The present research has some limitations. First, generalization of the results is somewhat limited. Since participants were composed of university students living in Turkey, it is difficult to generalise to all university students. Thus, it is important to investigate the variables studied in this research on different sample groups. Secondly, although structural equation modeling suggests results related to causality, it is difficult to explain causality among the variables examined in the 
Çağlayan Mülazım, Ö., \& Eldeleklioğlu, J. (2016). What is the role of self-compassion on subjective happiness and life satisfaction? Journal of Human Sciences, 13(3), 3895-3904. doi:10.14687/jhs.v13i3.4001

study, since correlational data were used. Thirdly, the findings of this study are of explanatory characteristics because it was intended to build a new model rather than testing the old one. Hence, it would be more appropriate to not take the findings as definite until it is tested on another sample. And lastly, the data reported here for self-compassion, subjective happiness, and life satisfaction are limited to self-reported data.

\section{Recommendations}

To conclude, the results of the study indicated that the dimensions of self-compassion may be important predictors of subjective happiness and life satisfaction. It has been clarified that as common humanity and mindfulness increased, subjective happiness and life satisfaction increased as well. On the contrary, as self-judgment, isolation, and over-identification increased, subjective happiness and life satisfaction decreased. People who are high in common humanity and mindfulness are happier and have higher life satisfaction than people high in self-judgment, isolation, and over-identification. As mentioned before, self-compassion is closely related to mental health, and the findings of this study are consistent with the previous studies. Since self-compassion is a new term, especially, in Turkey, the results of the present study will shed light on the literature. The findings may offer valuable information to psychological counselors and other mental health workers about the role of self-compassion on subjective happiness and life satisfaction. Practitioners may help clients increase their awareness about self-compassion by providing clients with individual counseling. Also, various counseling and psycho-educational programs can be organized to increase individuals' self-compassion. However, it is important to note that further research examining the relationship between self-compassion, subjective happiness and life satisfaction is needed to support the present study.

\section{References}

Akın, Ü., Akın, A., \& Abac1, R. (2007). Self-compassion: A study of validity and reliability. Hacettepe University Journal of Educational, 33, 1-10.

Akın, A., \& Akın, A. (2014). An investigation of the predictive role of self-compassion on subjective happinessin Turkish university students. Education Science and Psychology, 6(32), 5968.

Allen, A. B. (2011). Understanding the self-compassionate mindset in older adults. (Doctoral dissertation, Duke University, Duke). Retrieved from http://dukespace.lib.duke.edu/

Barnard, K. L., \& Curry, J. F. (2011). Self-compassion: Conceptualizations, correlates, and interventions. Review of General Psychology, $15 \quad$ (4), 289-303. http://dx.doi.org/10.1037/a0025754

Breen, W.E., \& Kashdan, T.B., \& Lenser, M.L., \& Fincham, F.D. (2010). Gratitude and forgiveness: Convergence and divergence on self-report and informant ratings. Personality and individual differences, 49, 932-937.

Bulut-Serin, N., \& Serin, O., \& Özbaş, L. F. (2010). Predicting university students' life satisfaction by their anxiety and depression level. Social and Behavioral Sciences, 9, 579-582. http://dx.doi.org/10.1016/i.sbspro.2010.12.200

Chaplin, T. M. (2006). Anger, happiness, and sadness: Associations with depressive symptoms in late adolescence. Journal of Youth and Adolescence, 35, 977-986. http://dx.doi.org/10.1007/s10964-006-9033-x

Diener, E. (2000). Subjective well-being: The science of happiness and a proposal of a national index. American Psychologist, 55, 34-43.

Diener, E., Emmons, R. A., Larsen, R. J., \& Griffin, S. (1985). The satisfaction with life scale. Journal of Personality Assessment, 40, 71-75. 
Çağlayan Mülazım, Ö., \& Eldeleklioğlu, J. (2016). What is the role of self-compassion on subjective happiness and life satisfaction? Journal of Human Sciences, 13(3), 3895-3904. doi:10.14687/jhs.v13i3.4001

Diener, E., \& Lucas, R. E. (2000). Explaining differences in social levels of happiness: relative standards, need fulfillment, culture, and evaluation theory. Journal of Happiness Studies, 1, 4778.

Diener, E., \& Seligman, M. E. (2002). Very happy people. Psychological Science, 13, 81-84.

Durak, M., \& Senol-Durak, E., \& Gencoz, T. (2010). Psychometric Properties of the Satisfaction with Life Scale among Turkish university students, correctional, officers, and elderly adults. Social Indicators Research, 99, 413-429.

Edwards, L. M., \& Lopez, S. J. (2006). Perceived family support, acculturation, and life satisfaction in Mexican American youth: A mixed-methods exploration. Journal of Counseling Psychology, 53(3), 279-287. http://dx.doi.org/10.1037/0022-0167.53.3.279

Gilbert, P. (Ed.). (2005). Compassion: Conceptualizations, research and use in psychotherapy. New York: Routledge.

Goodwin, R.,\& Cook, O., \& Yung, Y. (2001). Loneliness and life satisfaction among three cultural groups. Personal Relationships, 8, 225-230. http://dx.doi.org/10.1111/j.1475$\underline{6811.2001 . t b 00037}$

Krieger, T., Altenstein, D., Baettig, I., Doerig, N., \& Holtforth, M.G. (2013). Self-compassion in depression: Associations with depressive symptoms, rumination, and avoidance in depressed outpatients. Behavior Therapy, 44, 501-513

Le, T.N., \& Lai, M., \& Wallen, J. (2009). Multiculturalism and subjective happiness as mediated by cultural and relational variables. Cultural Diversity and Ethnic Minority Psychology. 15(3), 303313.

Leary, M. R., \& Tate, E. B., \& Adams, C. E., \& Allen, A. B., \& Hancock, J. (2007). Self-compassion and reactions to unpleasant self-relevant events: The implications of treating oneself kindly. Journal of Personality and Social Psychology, 92, 887-904.

Liem, J.H., \& Lustig, K., \& Dillon, C. (2010) Depressive symptoms and life satisfaction among Emerging Adults: A comparison of high school dropouts and graduates. Journal of Adult Development. 17,1, 33-44. http://dx.doi.org/10.1007/s10804-009-9076-9

Lyubomirsky, S. (2001). Why are some people happier than others? The role of cognitive and motivational processes in wellbeing. American Psychologist, 56, 239-249. http://dx.doi.org/10.1037//0003-066X.56.3.239

Lyubomirsky, S., \& Lepper, H. (1999). A measure of subjective happiness: Preliminary reliability and construct validation. Social Indicators Research, 46, 137- 155.

Lyubomirsky, S., Tucker, K. L., Caldwell, N. D., \& Berg, K. (1999). Why ruminators are poor problem solvers: clues from the phenomenology of dysphoric rumination. Journal of Personality and Social Psychology, 77, 1041-1060.

Mistler, B. (2010). Forgiveness, perfectionism and the role of compassion. Unpublished dissertation. University of Florida, Florida.

Myers, G. M., \& Diener, E. (1995). Who is happy? PsychologicalScience, 6, 10-17.

Neff, K. D. (2003a). Self-compassion: An alternative conceptualization of a healthy attitude toward oneself. Self and Identity, 2, 85-102. http://dx.doi.org/10.1080/15298860309032

Neff, K. D. (2003b). Development and validation of a scale to measure self-compassion. Self and Identity, 2, 223-250.

Neff, K. D. (2004). Self-compassion and psychological well-being. Constructivism in the Human Sciences, 9, 27-37.

Neff, K. D., Beretvas, S. N. (2013). The role of self-compassion in romantic relationships. Self and Identity, 12(1), 78-98. doi: http://dx.doi.org/10.1080/15298868.2011.639548

Neff, K. D., \& Germer, C. K. (2012). A Pilot Study and Randomized Controlled Trial of the Mindful Self-Compassion Program. Journal of Clinical Psychology, 1-17. http://dx.doi.org/10.1002/jclp.21923 
Çağlayan Mülazım, Ö., \& Eldeleklioğlu, J. (2016). What is the role of self-compassion on subjective happiness and life satisfaction? Journal of Human Sciences, 13(3), 3895-3904. doi:10.14687/jhs.v13i3.4001

Neff, K. D., \& Hseih, Y., \& Dejitthirat, K. (2005). Self-compassion, achievement goals, and coping with academic failure. Self and Identity, 4, 263-287. http://dx.doi.org/10.1080/13576500444000317

Neff, K. D., Kirkpatrick, K. \& Rude, S. S. (2007). Self-compassion and its link to adaptive psychological functioning. Journal of Research in Personality, 41, 139-154. http://dx.doi.org/10.1016/j.jpp.2006.03.004

Neff, K. D., \& McGehee, P. (2010). Self-compassion and psychological resilience among adolescents and young adults. Self and Identity, 9(3), 225-240. http://dx.doi.org/10.1080/15298860902979307

Neff, K. D., Pisitsungkagarn, K., \& Hsieh, Y. P. (2008). Self-compassion and self-construal in the United States, Thailand, and Taiwan. Journal of Cross-Cultural Psychology, 39, 267-285. http://dx.doi.org/10.1177/0022022108314544

Pavot, W., \& Diener, E. (1993). Review of the Satisfaction with Life Scale. Psychological Assessment, 5 (2), 164-172.

Savi-Çakar, F., \& Tagay, Ö., \& Karataş, Z.(2015). Adolescents' life satisfaction: Risky behaviors and hopelessness. International Journal on Nen Trends in Education and Their Implications, 6(1), 13096249.

Schiffrin, H. H., \& Nelson, S. K. (2010). Stressed and happy? Investigation of the relationship between happiness and perceived stress. Journal of Happiness Studies, 11, 33-39. http://dx.doi.org/10.1007/s10902-008-9104-7

Seligman, M., \& Csikszentmihalyi, M. (2000). Positive psychology: An introduction. American Psychologist, 55, 5-14. http://dx.doi.org/10.1037//0003-066X.55.1.5

Sheldon, K. M., \& King, L. (2001). Why positive psychology is necessary? American Psychologist, 56, 216-217. http://dx.doi.org/10.1037/0003-066X.56.3.216

Siahpush, M., \& Spittal, M., \& Singh, G. K. (2008). Happiness and life satisfaction prospectively predict self-rated health, physical health, and the presence of limiting, long-term health conditions. American Journal of Health Promotion, 23, 18-26.

Smeets, E., \& Neff, K., \& Alberts, H., \& Peters, M. (2014). Meeting suffering with kindness: Effects of a brief self-compassion intervention for female college students. Journal of clinical psychology,70(9), 794-807. http://dx.doi.org/10.1002/jclp.22076

Umphrey, L. R., \& Sherblom, J. C., (2014). The relationship of hope to self-compassion, relational social skill, communication apprehension, and life satisfaction. International Journal of Wellbeing, 4(2), 1-18. http://dx.doi.org/10.5502/ijw.v4i2.1

Uysal, R. (2014). Life satisfaction and self-compassion: A structural equation modelling. International Journal of Current Research, 6(6), 7251-7256.

Uysal, R., Satıc1, A. S., Satıc1, B., \& Akin, A. (2014). Subjective vitality as moderator of the relationship between life satisfaction and subjective happiness. Educational Science: Theory \& Practice, 14, 489-497. http://dx.doi.org/10.12738/estp.2014.2.1828 